\title{
PENGETAHUAN ANGGOTA KORPS SUKARELA PALANG M ERAH INDONESIA (KSR PMI) UNIT UNIVERSITAS NEGERI JAKARTA MENGENAI PENANGANAN CEDERA OLAHRAGA
}

\author{
Dela Listiyanto $^{1}$, Ruliando Hasea Purba ${ }^{2,}$ Ramdan Pelana ${ }^{2}$. \\ ${ }^{1}$ Program Studi Ilmu Keolahragaan \\ ${ }^{2}$ Fakultas Ilmu Keolahragaan Universitas Negeri Jakarta, Kampus B, Jakarta
}

\begin{abstract}
Abstrak: Penelitian ini memiliki tujuan untuk Mengetahui Pengetahuan Anggota Korps Sukarela Palang Merah Indonesia (KSR PMI) Unit Universitas Negeri Jakarta Mengenai Penanganan Cedera Olahraga. Penelitian ini dilakukan di seketariat Jl. Rawamangun Muka, Kampus A UNJ Gd. G Lantai 1 No.103 Jakarta Timur 13220. Pada tanggal 1 Juni 2016. Penelitian ini menggunakan metode deskriptif dengan teknik survey penyebaran angket sebagai instrumen dalam pengumpulan data, sampel yang digunakan yaitu seluruh anggota aktif Korps Sukarela Palang Merah Indonesia (KSR PMI) Unit Unversitas Negeri Jakarta Tahun 2016 yang berjumlah 35 orang, pengambilan sampel dengan menggunakan teknik total sampling. Instrumen penelitian menggunakan kuesioner yang di gunakan berbentuk pernyataan dengan menggunakan Skala Guttman.

Hasil penelitian menunjukan: Anggota Korps Sukarela Palang Merah Indonesia (KSR PMI) Unit Universitas Negeri Jakarta memiliki Pengetahuan Mengenai Penanganan Cedera Olahraga menujukan sebesar 29 anggota memiliki pengetahuan yang baik, sebanyak 6 anggota memilki pengetahuan cukup, Nilai Rata-Rata Pengetahuan Anggota KSR PMI Unit UNJ 79\% memiliki pengetahuan yang baik.
\end{abstract}

\section{Kata Kunci: Pengetahuan, Anggota Korps Sukarela Palang Merah Indonesia (KSR PMI) Unit UNJ, Cedera Olahraga}

\section{PENDAHULUAN}

Perkembangan zaman saat ini yang begitu pesat menuntut masyarakat untuk dapat mampu mengikuti perubahan-perubahan yang terjadi akibat pesatnya perkembangan Ilmu Pengetahuan dan Teknologi di dalam berbagai aspek kehidupan. Masyarakat semakin sibuk akan rutinitas yang dilakukan demi menghadapi tuntutan zaman, sehingga masyarakat sadar akan pentingnya olahraga terhadap kebutuhan jasmani guna menjaga kondisi dan stamina untuk menghadapi dunia kerja maupun rutinitas lainnya.
Kesehatan tubuh atau kesehatan jasmani merupakan suatu yang sangat berharga dibanding hal lain di dunia ini. Manusia dapat melakukan segala aktifitas dan rutinitas sehari-hari tentunya dalam keadaan sehat. Banyaknya harta dan kekayaan tidak menjamin seseorang hidup bahagia dan menderita apabila ia dalam keadaan sakit. Untuk itulah masyarakat sekarang ini di anjurkan menyempatkan diri untuk berolahraga di sela-sela kesibukannya demi pemenuhan kebutuhan jasmani.

Saat ini olahraga sudah jadi kebutuhan masyarakat luas, hal ini 
terbukti dari berkembangnya pusatpusat olahraga serta dipenuhinya ruangruang publik pada hari libur oleh masyarakat yang berolahraga baik pada masyarakat awam golongan dengan sosial ekonomi yang rendah sampai yang paling baik. Hal ini menunjukkan bahwa olahraga bukan hanya sekedar kebutuhan, namun sudah menjadi gaya hidup. Mereka berolahraga untuk menjaga kesehatan dan kebugaran tubuh, tidak sedikit juga dari mereka yang melakukannya karena hobi atau mengejar prestasi. Sebagian besar masyarakat melakukan olahraga yang bertujuan untuk memelihara kesehatan dan meningkatkan kebugaran jasmani. Namun kegiatan olahraga tersebut tidak didasari dengan pengetahuan akan dampak yang dialami oleh masyarakat khususnya pencegahan dan penanganan cedera olahraga.

Untuk mencegah terjadinya cedera olahraga, ada baiknya masyarakat mengetahui beberapa jenis cedera dan gerak penyebab terjadinya cedera sehingga dengan pengetahuan masyarakat mengetahui tentang jenis cedera olahraga dan bagaimana cara penanganannya. Meskipun demikian, cara yang lebih efektif dalam mengatasi cedera adalah dengan memahami beberapa jenis cedera dan mengenali bagaimana tubuh kita serta memberikan respon terhadap cedera tersebut, sehingga dapat mengetahui apa yang harus dilakukan untuk mencegah terjadinya cedera, bagaimana mendekteksi suatu cedera agar tidak terjadi parah, bagaimana mengobatinya dan kapan meminta pengobatan secara professional seperti memeriksakannya ke dokter. Akan tetapi penyembuhan juga tergantung dari derajat kerusakan yang di derita dan cepat lambat serta ketepatan penanggulangan secara dini.

Korps Sukarela Palang Merah Indonesia (KSR PMI) Unit Universitas
Negeri Jakarta merupakan salah satu unit kegiatan kemahasiswaan yang berada di Universitas Negeri Jakarta dan berkoordinasi di bawah PMI Kota Admistrasi Jakarta Timur. Korps Sukarela Palang Merah Indonesia (KSR PMI) Unit Universitas Negeri Jakarta juga organisasi yang bergerak dalam bidang kepalang merahan. Korps Sukarela Palang Merah Indonesia (KSR PMI) Unit Universitas Negeri Jakarta merupakan wadah bagi seluruh mahasiswa Universitas Negeri Jakarta yang ingin menyalurkan bakat dan minatnya dalam berorganisasi, membina rasa kesetiakawanan sosial dan mempunyai rasa kemanusiaan yang tinggi. Korps Sukarela Palang Merah Indonesia (KSR PMI) Unit Universitas Negeri Jakarta berdiri pada tanggal 10 Mei 1994 dengan pendirinya bernama Rita Nur Syiati, dimana pada waktu itu bermula dari nama Tim Kesehatan MENWA (Resimen Mahasiswa). Terbentuknya Korps Sukarela Palang Merah Indonesia (KSR PMI) Universitas Negeri Jakarta ini dilatar belakangi oleh kebutuhan dari seluruh instansi civitas kampus dan rekan-rekan unit kegiatan kemahasiswaan. Maka atas latar belakang tersebut Rita Nur Syiati membuat inisiatif dan mengajak anggota MENWA (Resimen Mahasiswa) lain untuk membentuk unit kegiatan lain dan memisahkan diri dari MENWA (Resimen Mahasiswa) setelah mendapat perijinan dari Komandan MENWA (Resimen Mahasiswa) Universitas Negeri Jakarta.

Kemudian terbentuklah unit kegiatan kemahasiswaan yang bergerak dalam hal kepalangmerahan dan kemanusiaan yang dikenal dengan nama Korps Sukarela Palang Merah Indonesia (KSR PMI) Unit IKIP. Di tanggal 20 November 1999 berubah menjadi Korps Sukarela Palang Merah Indonesia (KSR PMI) Unit Universitas Negeri Jakarta, 
kemudian pada tahun 2003 berubah menjadi Korps Sukarela Palang Merah Indonesia (KSR PMI) Universitas Negeri Jakarta. Tahun 2008 berubah kembali menjadi Korps Sukarela Palang Merah Indonesia (KSR PMI) Unit Universitas Negeri Jakarta, perubahan nama yang terjadi di karenakan ketentuan dari Palang Merah Indonesia (PMI).

Korps Sukarela Palang Merah Indonesia (KSR PMI) Unit Universitas Negeri Jakarta terus berupaya meningkatkan kemampuan kepalang merahan dalam upaya mengantisipasi banyaknya kejadian-kejadian di lingkungan kita yang membutuhkan pertolongan pertama dan banyaknya bencana alam yang terjadi di indonesia sebagai wujud mengamalkan salah satu Tri Dharma Perguruan Tinggi yaitu pengabdian kepada masyarakat.

Dalam melaksanakan tugasnya terkait kepalangmerahan Korps Sukarela Palang Merah Indonesia (KSR PMI) Unit Universitas Negeri Jakarta sendiri melakukan pelatihan dan pembinaan terhadap anggotanya yang bertujuan agar anggota dapat mengembangkan kepribadian, bakat, dan kemampuan di berbagai bidang di luar bidang akademik.

Kemampuan anggota Korps Sukarela Palang Merah Indonesia (KSR PMI) Unit Universitas Negeri Jakarta adalah salah satu kunci keberhasilan Korps Sukarela Palang Merah Indonesia (KSR PMI) Unit Universitas Negeri Jakarta dalam melaksanakan tugastugasnya. Pembinaan yang dilakukan Korps Sukarela Palang Merah Indonesia (KSR PMI) Unit Universitas Negeri Jakarta yaitu melakukan program kegiatan internal, kegitan eksternal (kegiatan bermitra dengan PMI dan kegiatan dengan KSR Perti SeIndonesia).
Kegiatan internal seperti PCAB (Penerimaan Calon Anggota Baru), Pelatihan Dasar Keorganisasian dan Slayer, LARUT (Latihan Rutin), Olahraga Rutin, Donor Darah, Pelatihan Fasilitator PMR, Pelatihan PPCO, Pengiriman Utusan Tim Kesehatan, Program PMR Binaan, Pengiriman Utusan Pesonil Pelatihan, Daerah Binaan KPPBM, Reuni Akbar, Anjangsana Dan Audiensi, Mading, Bulletin, HUT KSR, Buka Puasa Bersama, Sosialisasi MPA.

Kegiatan Kemitraan dengan PMI seperi pelatihan Pendidikan Remaja Sebaya Se-Jaktim, Pelatihan SATGANA Se-Jaktim, Pelatihan Assessment Se-DKI Jakarta, Pelatihan Ambulance Crew Se-Jaktim, Pelatihan Management Pelatihan Se-DKI Jakarta, Pelatiahan Logistik Se-Jaktim, Temu Karya KSR-TSR Se-Indonesia, Pelatihan SATAGANA Nasional, Pengiriman Relawan Bencana Jatuhnya Pesawat Air Asia, Pelatihan Pengenalan dan Penggunaan Alat-alat Ambulance, Pelatihan Fasilitator PMR (Mula, Madya, dan Wira), Panitia Jumbara PMR Se-DKI Jakarta, Penanggulangan Bencana di Rawamangun.

Kegiatan dengan KSR Perti SeIndonesia seperti Pelatihan Pshycosocial Support Program di UPI Bandung, Gladian Relawan VI di Lampung, Temu Bhakti KSR di Bali, Pelatihan Nasional KSR Perti SAR Air di Universitas Mahasaraswati Denpasar. Yang dimaksud dengan Sport Injuries (Cedera Olahraga) ialah segala macam cedera yang timbul, baik pada waktu latihan maupun pada waktu berolahraga (pertandingan) ataupun sesudahnya. Bagian yang biasanya mengalami cedera ialah tulang, otot, tendo, serta ligamentum. Namun cedera yang di alami oleh masyarakat akan berkembang tidak baik apabila anggota Korp Sukarela Palang Merah Indonesia 
(KSR PMI) Unit Universitas Negeri Jakarta tidak memberikan pengetahuan mengenai pencegahan dan penanganan cedera olahraga dengan benar. Meskipun demikian, penanganan rehabilitasi medik yang benar harus sesuai dengan kondisi cedera maka sikap pertama harus berupa penyelamatan. Setelah diketahui tidak ada hal yang membahayakan dan hal tersebut telah teratasi maka dilanjutkan dengan melakukan metode RICE.

Permasalahan cedera olahraga bermula dari adanya suatu kejadian gerak olahraga yang berlangsung secara berulang-ulang dalam jangka waktu lama sehingga biasanya memerlukan pertolongan yang professional dengan segera. Maka jenis cedera ini terkadang memberikan respon yang baik bagi pengobatan sendiri. Permasalahan ini biasanya terjadi akibat kelelahan berlebihan karena terlalu banyak partai pertandingan yang harus di ikuti.

Jadi dapat disimpulkan bahwa Anggota Korp Sukarela Palang Merah Indonesia (KSR PMI) Unit Universitas Negeri diharapkan mempunyai pengetahuan penanganan cedera olahraga dengan benar sehingga tidak menimbulkan kerukasakan yang lebih.

\section{Tinjauan Pustaka.}

\section{Hakikat Pengetahuan}

Pengetahuan adalah suatu istilah yang dipergunakan untuk menuturkan apabila seseorang mengenal tentang sesuatu. Suatu hal yang menjadi pengetahuan adalah selalu terdiri atas unsur yang mengetahui dan diketahui serta kesadaran mengenai hal yang ingin diketahuinya itu.

Pengetahuan adalah segenap apa yag diketahui manusia tentang suatu objek tertentu, termasuk ilmu". Ini dimaksudkan setelah seseorang mendapatkan infomasi baru, maka seseorang akan cenderung lebih mengerti degan apa yang baru saja diterimanya.

Pengetahuan pada dasarnya merupakan pengalaman-pengalaman yang di dapat seseorang. Baik ketika berada disuatu lembaga pendidikan ataupun dikhidupan sehari-harinya yang diterima melalui pengindraan seperti melihat, mendengar ataupun merasakan.

Keterarahan ini dimaksudkan jika manusia terhadap objek hanya mungkin menimbulkan pengetahuan jika dalam diri manusia sebagai subjek sudah terdapat kesamaan-kesamaan prinsip atau katagori tertentu yang memungkinkan manusia dapat mengenal dan menangkap objek yang diamatinya. Dengan kata lain, pengetahuan itu hanya mungkin terwujud jika manusia sendiri adalah bagian objek. Ciri manusia berpengetahuan itu adalah "manusia yang hidup, hidup bermakna. Manusia bertindak, berlaku dan berbuat. Dalam kehidupan manusia membutuhkan pengetahuan untuk melakukan, berbuat dan bertindak. Maka dari itu, dipercaya seseorang yang mempunyai pengetahuan akan memiliki nilai hidup lebih bermakna, dengan demikan bahwa pengetahuan adalah peristiwa yang terjadi dalam diri manusia. Manusia sebagai objek pengetahuan memegang peran penting, keterarahan manusia terhadap objek merupakan faktor yang menentukan bagi munculnya pengetahuan manusia. Dengan kata lain pengetahuan itu hanya terwujud jika manusia sendiri adalah sebagian objek dari realitas alam semesta ini.

Dimyati dan Mujiyono mendefinisikan menurut taksonomi bloom (penggolongan) tingkatan ranah kognitif diurutkan menjadi enam tingkatan, yaitu :

1. Pengetahuan (Knowledge), merupakan tingkatan terendah dari ranah kognitif, pengetahuan ialah 
proses dalam mengingat dan mengungkapkan kembali informasi yang diperoleh secara tepat sesuai dengan informasi yang disampaikan.

2. Pemahaman (Comperhension), berisikan kemampuan untuk memaknai dengan tepat apa yang telah dipelajari tanpa harus menerapkannya.

3. Penerapan (Application), pada tingkat ini seseorang memiliki kemampuan untuk menerapkan gagasan, prosedur, metode, rumus teori sesuai dengan situasi konkrit.

4. Analisis (Analysis), kemampuan menganalisa informasi yang masuk dan menstrukturkan informasi ke dalam bagian yang lebih kecil untuk mengenali pola atau hubungannya.

5. Sintesis (Synthesis), kemampuan untuk mampu menjelaskan struktur dari sebuah kondisi yang sebelumnya tak dikenal dan mampu mengenali informasi yang harus didapat untuk menghasilkan solusi yang dibutuhkan.

6. Evaluasi (Evaluation), kemampuan untuk memberikan penilaian berupa solusi, gagasan, metodologi dengan menggunakan kriteria yang cocok untuk memastikan nilai efektifitas atau manfaatnya.

Dari teori tersebut disimpulkan bahwa pengetahuan selalu terdiri atas unsur yang mengetahui dan diketahui serta kesadaran mengenai hal yang ingin diketahuinya. Pengetahuan selalu menuntut adanya subjek yang mempunyai kesadaran untuk megetahui tentang sesuatu yang dihadapinya sebagai hal yang ingin diketahuinya. Jadi bisa dikatakan pengetahuan hasil tahu manusia terhadap sesuatu, atau segala perbuatan manusia untuk memahami suatu objek yang dihadapinya atau hasil usaha manusia untuk memahami suatu objek tertentu.

\section{Hakikat Korp Sukarela Palang Merah Indonesia (KSR PMI) Unit Universitas Negeri Jakarta}

Korps Sukarela Palang Merah Indonesia (KSR PMI) Unit Universitas Negeri Jakarta merupakan salah satu unit kegiatan kemahasiswaan yang berada di Universitas Negeri Jakarta dan berkoordinasi di bawah PMI Jakarta Timur. Korps Sukarela Palang Merah Indonesia (KSR PMI) Unit Universitas Negeri Jakarta juga organisasi yang bergerak dalam bidang kepalang merahan. Korps Sukarela Palang Merah Indonesia (KSR PMI) Unit Universitas Negeri Jakarta merupakan wadah bagi seluruh mahasiswa Universitas Negeri Jakarta yang ingin menyalurukan minat dan bakatnya dalam berorganisasi, membina rasa kesetiakawanan sosial dan mempunyai rasa kemanusiaan yang tinggi, serta terus berupaya meninkatkan kemamuan kepalagmerahan dalam upaya mengatasi banyak kejadian yang memerlukan pertolongan pertama.

Pada hakikatnya anggota Korp Sukarela Palang Merah Indonesia (KSR PMI) Unit Universitas Negeri Jakarta di kampus berkewajiban memberikan pelayanan kesehatan kepada mahasiswa dan masyarakat. Anggota Korp Sukarela Palang Merah Indonesia (KSR PMI) Unit Universitas Negeri Jakarta berasal dari kalangan mahasiswa. Dalam keanggotaannya, Korp Sukarela Palang Merah Indonesia (KSR PMI) Unit Universitas Negeri Jakarta selalu memegang teguh prinsip kesukarelaan, artinya tidak ada paksaan atau tekanan untuk menjadi anggota Korp Sukarela Palang Merah Indonesia (KSR PMI) Unit Universitas Negeri Jakarta. Oleh karena itu, anggota-anggota Korp Sukarela Palang Merah Indonesia (KSR PMI) Unit Universitas Negeri Jakarta merupakan mahasiswa-mahasiswa yang terpilih dan benar-benar tergerak 
hatinya untuk menjadi anggota atas dasar jiwa sosial dan menolong sesama.

Korps Sukarela Palang Merah Indonesia (KSR PMI) Unit Universitas Negeri Jakarta mulai berdiri pada tangal 10 Mei 1994. Organisasi yang bergerak di bidang sosial kemanusiaan ini di bentuk dari mahasiswa dan mahasiswi universitas negeri Jakarta yang anggotanya berjumlah 35 orang dan masih aktif dan oleh peneliti di jadikan sampel penelitian.

Korps Sukarela Palang Merah Indonesia (KSR PMI) Unit Universitas Negeri Jakarta terus berbenah diri baik secara intern organisasi maupun ekstern organisasi. Kualitas dan kuantitas kegiatan juga terus di tingkatkan. Mulai dari konsolidasi anggota, kegiatan kemanusiaan dan sosial, pembenahan administrasi, sampai pada pemasyarakatan Korp Sukarela Palang Merah Indonesia (KSR PMI) Unit Universitas Negeri Jakarta. Hingga saat ini, telah banyak kegiatan yang bermanfaat yang di selenggarakan oleh Korp Sukarela Palang Merah Indonesia (KSR PMI) Unit Universitas Negeri Jakarta yang secara langsung maupun tidak langsung turut mengharumkan nama Universitas Negeri Jakarta.

Korp Sukarela Palang Merah Indonesia memiliki visi dan misi dalam kegiatanya, yaitu:

Visi

Mewujudkan KSR PMI Unit UNJ sebagai kegiatan mahasiswa yang andal di bidang kepalangmerahan dan keoganisasian.

Misi

1. Menjunjung tinggi dan mengamalkan nilai-nilai kepalangmerahan Serta Tri Darma Perguruan Tinggi (Pendidikan, Penelitian, Dan Pengabdian Kepada Masyarakat)

2. Mengembangkan sumber daya manusia KSR PMI Unit UNJ yang professional dalam bidang kepalangmerahan dan organisasi

3. Menjaga nilai-nilai norma yang berhubungan denan masyarakat

4. Membangun dan menjaga hubungan kerjasama dengan organisasi intern dan ekstern kampus.

\section{Hakikat Penanganan Cedera Olahraga}

Cedera adalah cacat atau luka akibat kecelakaan. Cedera merupakan rusaknya jaringan yang disebabkan adanya kesalahan teknis, benturan, atau aktivitas fisik yang melebihi batas beban latihan, yang dapat menimbulkan rasa sakit akibat dari kelebihan latihan melalui pembebanan latihan ang terlalu berat sehingga otot dan tulang tidak lagi dalam keadaan anatomis. Pada umumnya semua kegiatan olahraga mempunyai resiko cedera baik ringan maupun berat. Kemungkinan cedera sangat beragam tergantung dari jenis olahraga itu sendiri, penggunaan alat (media), maupun kecelakaan yang terjadi akibat kesalahan atletnya sendiri. Sangat disayangkan jika hanya karena cedera olahraga tersebut para pelaku olahraga sulit meningkatkan atau mempertahankan prestasi.

Sport injuries (cedera olahraga) adalah segala macam cedera yang timbul baik pada waktu latihan, pada waktu pertandingan, maupun sesudah pertandingan.

Jika usaha pencegahan sudah dilakukan secara maksimal, belum tentu potensi cedera bisa langsung menghilang. Potensi cedera sangat mungkin terjadi mengingat banyaknya faktor yang mempengaruhi. Cedera olahraga jika tidak ditangani dengan cepat dan benar akan mengakibatkan gangguan atau keterbatasan fisik, baik dalam melakukan aktivitas hidup seharihari maupun melakukan aktivitas olahraga yang bersangkutan. Bahkan 
bagi atlet cedera ini bisa berarti istirahat yang cukup lama dan mungkin harus meninggalkan sama sekali hobi dan profesinya. Dengan demikian setiap atlet tentunya ingin terhindar dari cedera olahraga. Banyak sekali penyebab-penyebab terjadi cedera yang harus diperhatikan, sehingga seseorang dapat menepis atau menghindari kecenderungan terjadinya cedera olahraga.

\section{KERANGKA BERPIKIR}

Aktifitas fisik menuntut pelakunya untuk bekerja lebih berat. Salah satu jenis aktivitas fisik yang membutuhkan kerja ekstra adalah olahraga. Kegiatan olahraga sangat rentan terjadi cedera akibat berbagai macam faktor seperti faktor instrinsik dan ekstrinsik. Olahraga juga merupakan suatu aktifitas untuk mendapatkan kebugaran jasmani dalam meningkatkan kemampuan fisik dan prestasi. Pada saat melakukan kegiatan fisik mungkin di dapat cedera apabila tidak dilakukan dengan benar.

Maka peran Korp Sukarela Palang Merah Indonesia (KSR PMI) unit Universitas Negeri Jakarta sangat diperlukan sebagai organisasi kepalangmerahan yang memberikan pertolonhan pertama dalam menangani cedera. Organisasi Kortp Sukarela Palang Merah Indonesia (KSR PMI) unit Universitas Negeri Jakarta mempunyai tugas kemanusiaan secara sukarela. Tujuan organisasi ini memberikan pertolongan kepada korban yang terluka. Disamping itu, pengetahuan mengenai penanganan cedera olahraga diharapkan dipahami secara benar sehingga cedera olahraga dapat teratasi dengan benar. Disamping itu agar tidak melakukan tindakan yang salah dalam penanganan korban yang mengalami cedera, maka Korp Sukarela Palang Merah Indonesia (KSR PMI)
Unit Universitas Negeri Jakarta membekali dirinya dengan ilmu pengetahuan bagaimana penanganannya sebelum membawanya ke dokter untuk penanganan yang lebih lanjut.

Oleh karena itu, betapa pentingnya Korp Sukarela Palang Merah Indonesia (KSR PMI) unit Universitas Negeri Jakarta memiliki pengetahuan bagaimana penanganan cedera agar dapat / mampu dalam melaksanakan tugas kepalangmerahan.

\section{METODE}

Penelitian ini menggunakan metode deskriptif yaitu suatu metode penelitian yang dilakukan dengan tujuan utama untuk membuat gambaran atau deskripsi tentang suatu keadaan secara objektif, dengan teknik survey penyebaran angket sebagai instrumen dalam pengumpulan data.

Instrumen Penelitian. Instrumen yang digunakan dalam penelitian ini adalah menggunakan kuesioner yang bersifat tertutup, yaitu kuesioner yang telah disediakan jawabannya sehingga responden tinggal memilih. Kuesioner yang digunakan berbentuk pernyataan.

Teknik Pengumpulan Data. Teknik pengumpulan data dalam penelitian ini yaitu dengan menggunakan angket. Teknik ini dilakukan dengan mrngedarkan suatu daftar pernyataan yang berupa angket, diajaukan secara tertulis kepada sejumlah responden untuk mendapatkan informasi, jawaban dan sebagainya. Dalam melakukan penelitian ini, tahap-tahap yang harus dilakukan, yaitu: pertama adalah menentukan populasi, menentukan jumlah sampel, menentukan waktu pengamatan data, lalu menyusun kisikisi pernyataan angket yang menggambarkan Tingkat Pengetahuan Korp Sukarela Palang Merah Indonesia (KSR PMI) Unit Universitas Negeri 
Jakarta tentang Penangan Cedera Olahraga..

\section{HASIL DAN PEMBAHASAN}

1. Pengetahuan Anggota Korps Sukarela Palang Merah Indonesia (KSR PMI) Unit Universitas Negeri Jakarta tentang Jenis-Jenis Cedera Olahraga

Dibawah ini disajikan data mengenai distrbusi frekuensi dan grafik histogram data Pengetahuan Anggota Korps Sukarela Palang Merah Indonesia (KSR PMI) unit Universitas Negeri Jakarta tentang jenis-jenis cedera olahraga.

Tabel 1. Deskripsi Nilai Statistik Dimensi Jenis-jenis Cedera Olahraga

\begin{tabular}{c|c} 
Ukuran Stastistik & Nilai Stastistik \\
\hline Nilai Terendah & 62 \\
\hline Nilai Tertinggi & 95 \\
\hline Rata-Rata & 81 \\
\hline Simpangan Baku & 29,46 \\
\hline Median & 81 \\
\hline Modus & 80.95 \\
\hline Range & 33
\end{tabular}

Tabel 2. Distribusi Frekuensi Dimensi Jenis-Jenis Cedera Olahraga

\begin{tabular}{l|l|c|c|c} 
No & $\begin{array}{l}\text { Kelas } \\
\text { Interval }\end{array}$ & $\begin{array}{l}\text { Nilai } \\
\text { Tengah }\end{array}$ & $\begin{array}{l}\text { Frekuensi } \\
\text { Absolut }\end{array}$ & $\begin{array}{l}\text { Frekuensi } \\
\text { Relatif }\end{array}$ \\
\hline 1 & $62-67$ & 64.5 & 4 & $11 \%$ \\
\hline 2 & $68-73$ & 70.5 & 3 & $9 \%$ \\
\hline 3 & $74-79$ & 76.5 & 4 & $11 \%$ \\
\hline 4 & $80-85$ & 82.5 & 8 & $23 \%$ \\
\hline 5 & $86-91$ & 88.5 & 12 & $34 \%$ \\
\hline 6 & $92-97$ & 94.5 & 4 & $11 \%$ \\
\hline \multicolumn{2}{l|}{ Jumlah } & 35 & $100 \%$
\end{tabular}

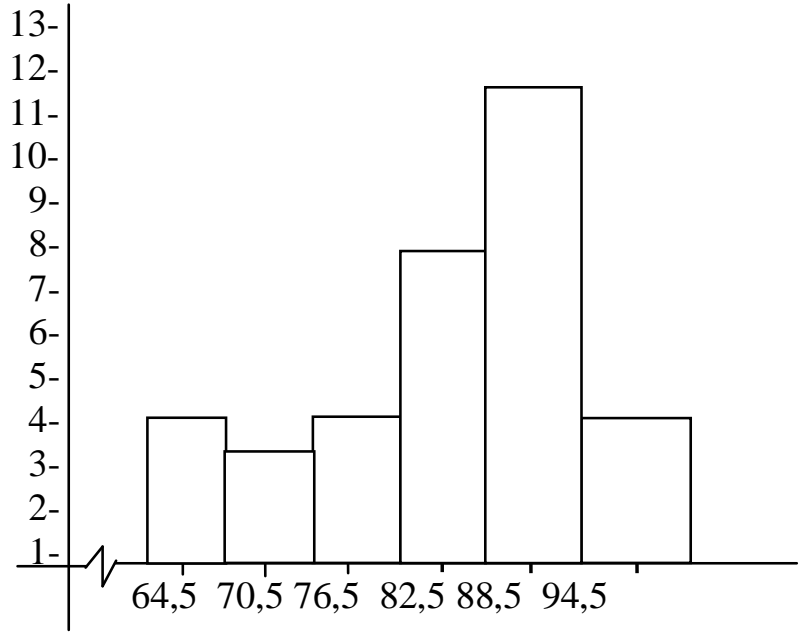

Gambar 1.. Histogram Jenis-Jenis Cedera Olahraga

Data di atas memberikan informasi Pengetahuan Anggota Korps Sukarela Palang Merah Indonesia (KSR PMI) Unit Universitas Negeri Jakarta tentang jenis-jenis cedera olahraga dengan nilai tertinggi sebesar 95 dan nilai terendah 62 , dengan rentang nilai 33 dan nilai rata-rata 81 .

Dari hasil perhitungan dimensi, terdapat 4 anggota KSR PMI Unit UNJ yang dapat menjawab semua pernyataan 20 soal dengan benar, sebanyak 5 anggota KSR PMI Unit UNJ menjawab 19 soal dengan benar, sebanyak 7 anggota KSR PMI Unit UNJ menjawab 18 soal dengan benar, sebanyak 8 anggota KSR PMI Unit UNJ menjawab 17 soal dengan benar, sebanyak 4 anggota KSR PMI Unit UNJ menjawab 16 soal dengan benar, sebanyak 3 anggota KSR PMI Unit UNJ menjawab 15 soal dengan benar, sebanyak 1 anggota KSR PMI Unit UNJ menjawab 14 soal dengan benar, sebanyak 3 anggota KSR PMI Unit UNJ menjawab 13 soal dengan benar. 
2. Pengetahuan Anggota Korps

Sukarela Palang Merah Indonesia (KSR PMI) Unit Universitas Negeri Jakarta tentang Derajat Cedera Olahraga

Di bawah ini disajikan data mengenai distribusi frekuensi dan grafik histogram data Pengetahuan Anggota Korps Sukarela Palang Merah Indonesia (KSR PMI) Unit Universitas Negeri Jakarta tentang derajat cedera olahraga.

Tabel 3.. Deskripsi Nilai Stastistik Derajat Cedera Olahraga

\begin{tabular}{c|c} 
Ukuran Stastistik & Nilai Stastistik \\
\hline Nilai Terendah & 60 \\
\hline Nilai Tertinggi & 100 \\
\hline Rata-Rata & 87 \\
\hline Simpangan Baku & 18,21 \\
\hline Median & 80 \\
\hline Modus & 80 \\
\hline Range & 40
\end{tabular}

Tabel 4. Distribusi Frekuensi Dimensi Derajat Cedera Olahraga

\begin{tabular}{c|c|c|c|c} 
No & $\begin{array}{c}\text { Kelas } \\
\text { Interval }\end{array}$ & $\begin{array}{c}\text { Nilai } \\
\text { Tengah }\end{array}$ & $\begin{array}{c}\text { Frekuensi } \\
\text { Absolut }\end{array}$ & $\begin{array}{c}\text { Frekuensi } \\
\text { Relatif }\end{array}$ \\
\hline 1 & $60-66$ & 63 & 1 & $3 \%$ \\
\hline 2 & $67-73$ & 70 & 0 & $0 \%$ \\
\hline 3 & $74-80$ & 77 & 20 & $57 \%$ \\
\hline 4 & $81-87$ & 84 & 0 & $0 \%$ \\
\hline 5 & $88-94$ & 91 & 0 & $0 \%$ \\
\hline 6 & $95-101$ & 98 & 14 & $40 \%$ \\
\hline \multicolumn{2}{|c|}{ Jumlah } & & 35 & $100 \%$
\end{tabular}

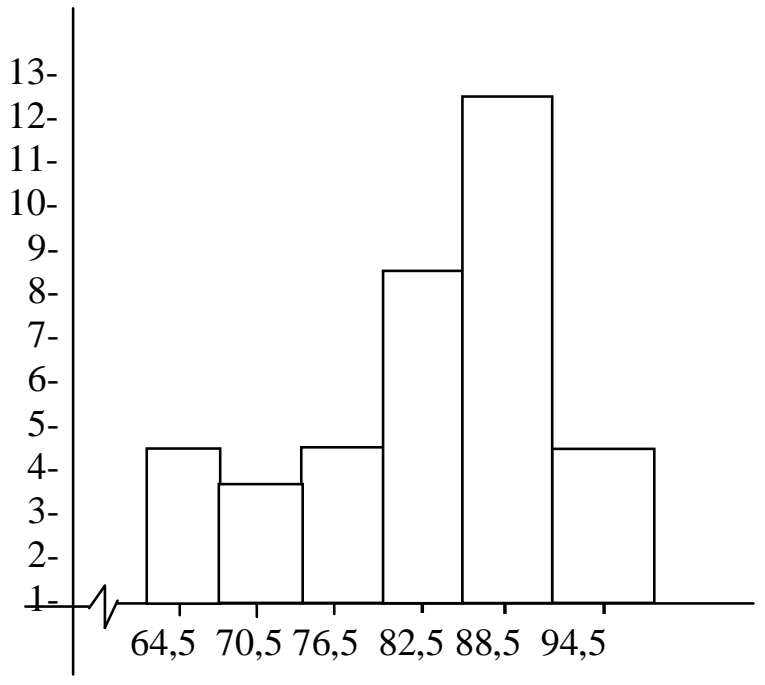

Gambar 2.. Histogram Jenis-Jenis Cedera Olahraga

Data di atas memberikan informasi Pengetahuan Anggota Korps Sukarela Palang Merah Indonesia (KSR PMI) Unit Universitas Negeri Jakarta tentang derajat cedera olahraga dengan nilai tertinggi sebesar 100 dan nilai terendah 60 , dengan rentang nilai 40 dan nilai rata-rata 87.

Dari hasil perhitungan dimensi terdapat 14 anggota KSR PMI Unit UNJ yang dapat menjawab semua pernyataan 5 soal dengan benar, sebanyak 20 anggota KSR PMI Unit UNJ menjawab 4 soal dengan benar, sebanyak 1 anggota KSR PMI Unit UNJ menjawab 3 soal dengan benar.

\section{Pengetahuan Anggota Korps Sukarela Palang Merah Indonesia (KSR PMI) Unit Universitas Negeri Jakarta tentang Sebab-Sebab Terjadinya Cedera Olahraga}

Di bawah ini disajikan data mengenai distribusi frekuensi dan grafik histogram data Pengetahuan Anggota Korps Sukarela Palang Merah Indonesia (KSR PMI) Unit Universitas Negeri Jakarta tentang sebab-sebab terjadiya cedera olahraga. 
Tabel 5. Deskripsi Nilai Stastistik Dimensi Sebab-Sebab Terjadinya Cedera Olahraga

\begin{tabular}{c|c} 
Ukuran Stastistik & Nilai Stastistik \\
\hline Nilai Terendah & 58 \\
\hline Nilai Tertinggi & 92 \\
\hline Rata-Rata & 76 \\
\hline Simpangan Baku & 16,81 \\
\hline Median & 75 \\
\hline Modus & 83,33 \\
\hline Range & 33
\end{tabular}

Tabel 6. Distribusi Frekuensi Dimensi Sebab-Sebab Terjadinya Cedera

\begin{tabular}{c|c|c|c|c} 
No & $\begin{array}{c}\text { Kelas } \\
\text { Interval }\end{array}$ & $\begin{array}{c}\text { Nilai } \\
\text { Tengah }\end{array}$ & $\begin{array}{c}\text { Frekuensi } \\
\text { Absolut }\end{array}$ & $\begin{array}{c}\text { Frekuensi } \\
\text { Relatif }\end{array}$ \\
\hline 1 & $58-63$ & 60.5 & 5 & $14 \%$ \\
\hline 2 & $64-69$ & 66.5 & 6 & $17 \%$ \\
\hline 3 & $70-75$ & 72.5 & 9 & $26 \%$ \\
\hline 4 & $76-81$ & 78.5 & 0 & $0 \%$ \\
\hline 5 & $82-87$ & 84.5 & 9 & $26 \%$ \\
\hline 6 & $88-93$ & 90.5 & 6 & $17 \%$ \\
\hline \multicolumn{2}{l|}{ Jumlah } & & 35 & $100 \%$
\end{tabular}

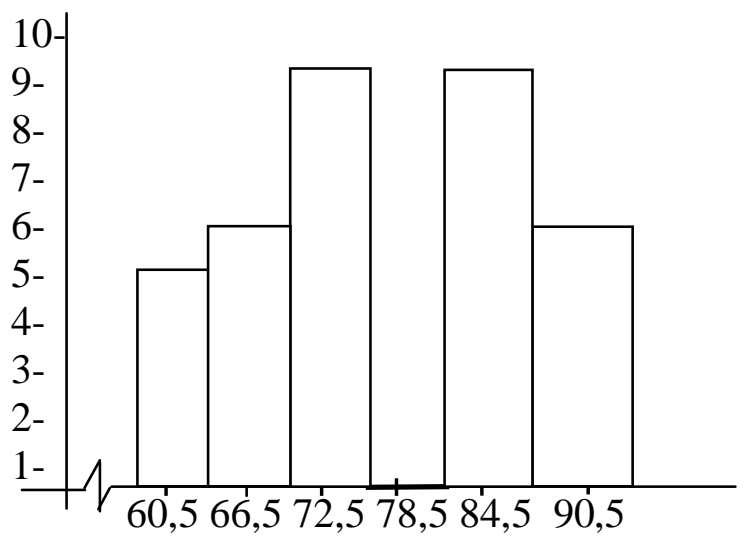

Gambar 3. Histogram Sebab-Sebab Terjadinya Cedera

Data di atas memberikan informasi Pengetahuan Anggota Korps Sukarela Palang Merah Indonesia (KSR PMI) Unit Universitas Negeri Jakarta tentang sebab-sebab terjadinya cedera olahraga dengan nilai tertinggi sebesar 92 dan nilai terendah 58, dengan rentang nilai 33 dan nilai rata-rata 76.
Dari hasil perhitungan dimensi terdapat 6 anggota KSR PMI Unit UNJ yang dapat menjawab semua pernyataan 11 soal dengan benar, sebanyak 9 anggota KSR PMI Unit UNJ menjawab 10 soal dengan benar, sebanyak 9 anggota KSR PMI Unit UNJ menjawab 9 soal dengan benar, sebanyak 6 anggota KSR PMI Unit UNJ menjawab 8 soal dengan benar, sebanyak 5 anggota KSR PMI Unit UNJ menjawab 7 soal dengan benar.Penanganan Cedera Olahraga Anggota Korps Sukarela Palang Merah Indonesia (KSR PMI) Unit Universitas Negeri Jakarta

Di bawah ini disajikan data mengenai distribusi frekuensi dan grafik histogram data Penanganan Cedera Olahraga Anggota Korps Sukarela Palang Merah Indonesia (KSR PMI) Unit Universitas Negeri Jakarta.

\section{Tabel 7. Deskripsi Nilai Stastistik Dimensi Penanganan Cedera Olahraga}

\begin{tabular}{c|c} 
Ukuran Stastistik & Nilai Stastistik \\
\hline Nilai Terendah & 67 \\
\hline Nilai Tertinggi & 100 \\
\hline Rata-Rata & 79 \\
\hline Simpangan Baku & 16,92 \\
\hline Median & 83 \\
\hline Modus & 83,33 \\
\hline Range & 33
\end{tabular}

Tabel 8. Distribusi Frekuensi Dimensi Penanganan Cedera Olahraga

\begin{tabular}{c|c|c|c|c} 
No & $\begin{array}{c}\text { Kelas } \\
\text { Interval }\end{array}$ & $\begin{array}{c}\text { Nilai } \\
\text { Tengah }\end{array}$ & $\begin{array}{c}\text { Frekuensi } \\
\text { Absolut }\end{array}$ & $\begin{array}{c}\text { Frekuensi } \\
\text { Relatif }\end{array}$ \\
\hline 1 & $67-72$ & 69.5 & 6 & $17 \%$ \\
\hline 2 & $73-78$ & 75.5 & 4 & $11 \%$ \\
\hline 3 & $79-84$ & 81.5 & 7 & $20 \%$ \\
\hline 4 & $85-90$ & 87.5 & 10 & $29 \%$ \\
\hline 5 & $91-96$ & 93.5 & 6 & $17 \%$ \\
\hline 6 & $97-102$ & 99.5 & 2 & $6 \%$ \\
\hline \multicolumn{2}{l|}{ Jumlah } & & 35 & $100 \%$
\end{tabular}




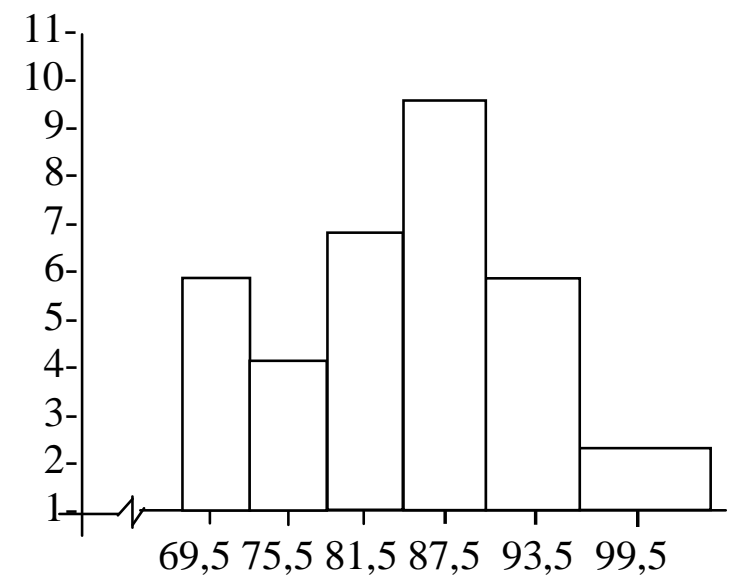

Gambar 4. Histogram Penanganan Cedera Olahraga

Data di atas memberikan informasi Penanganan Cedera Olahraga Anggota Korps Sukarela Palang Merah Indonesia (KSR PMI) Unit Universitas Negeri Jakarta dengan nilai tertinggi sebesar 100 dan nilai terendah 67, dengan rentang nilai 33 dan nilai ratarata 79.

Dari hasil perhitungan dimensi terdapat 2 anggota KSR PMI Unit UNJ yang dapat menjawab semua pernyataan 12 soal dengan benar, sebanyak 6 anggota KSR PMI Unit UNJ menjawab 11 soal dengan benar, sebanyak 10 anggota KSR PMI Unit UNJ menjawab 10 soal dengan benar, sebanyak 7 anggota KSR PMI Unit UNJ menjawab 9 soal dengan benar, sebanyak 10 anggota KSR PMI Unit UNJ menjawab 8 soal dengan benar.

Berdasarkan data yang di dapat dari berbagai pengukuran yang dilakukan dari masing-masing dimensi tentang Pengetahuan Anggota KSR PMI Unit UNJ tentang Jenis-Jenis Cereda, Derajat Cedera, Sebab-Sebab Terjadinya Cedera Olahraga dan Penanganan Cedera Olahraga Anggota KSR PMI Unit UNJ.

Analisis yang saya dapat dari Pengetahuan Anggota KSR PMI Unit UNJ tentang Jenis-Jenis Cedera menunjukan sebanyak 28 orang memiliki pengetahuan yang baik, sebanyak 7 orang memiliki pengetahuan yang cukup, Nilai Rata-Rata Pengetahuan Jenis-Jenis Cedera Anggota KSR PMI Unit UNJ 81\% memiliki pengetahuan yang baik. Pengetahuan Anggota KSR PMI Unit UNJ tentang Derajat Cedera menunjukan sebanyak 34 orang memiliki pengetahuan yang baik, sebanyak 1 orang memiliki pengetahuan yang cukup, Nilai Rata-Rata Pengetahuan Derajat Cedera Anggota KSR PMI Unit UNJ 87\% memiliki pengetahuan yang baik.

Pengetahuan Anggota KSR PMI

Unit UNJ tentang Sebab-Sebab Terjadinya Cedera menunjukan sebanyak 17 orang memiliki pengetahuan yang baik, sebanyak 18 orang memiliki pengetahuan yang cukup, Nilai Rata-Rata Pengetahuan Sebab-Sebab Terjadinya Cedera Anggota KSR PMI Unit UNJ 76\% memiliki pengetahuan yang baik.

Penanganan Cedera Olahraga Anggota KSR PMI Unit UNJ menunjukan sebanyak 18 orang memiliki pengetahuan yang baik, sebanyak 17 orang memiliki pengetahuan yang cukup, Nilai RataRata Pengetahuan Penanganan Anggota KSR PMI Unit UNJ 79\% memiliki pengetahuan yang baik.

Jika dilihat dari hasil prosentase Pengetahuan Anggota Korps Sukarela Palang Merah Indonesia (KSR PMI) Unit Universitas Negeri Jakarta Mengenai Penanganan Cedera Olahraga, maka anggota Korps Sukarela Palang Merah Indonesia (KSR PMI) Unit Universitas Negeri Jakarta mengetahui betul tentang Jenis-Jenis Cedera, Derajat Cedera, Sebab-Sebab Terjadinya Cedera dan Penanganan Cedera Olahraga ialah baik. 
PENUTUP

Kesimpulan. Berdasarkan hasil penelitian, maka dapat disimpulkan bahwa Anggota Korps Sukarela Palang Merah Indonesia (KSR PMI) Unit Universitas Negeri Jakarta memiliki Pengetahuan Mengenai Penanganan Cedera Olahraga menujukan sebesar 29 anggota memiliki pengetahuan yang baik, sebanyak 6 anggota memilki pengetahuan cukup, Nilai Rata-Rata Pengetahuan Anggota KSR PMI Unit UNJ $79 \%$ memiliki pengetahuan yang baik.

Saran. Berdasarkan kesimpulan di atas, maka dapat dikemukakan beberapa saran yang kiranya dapat bermanfaat bagi anggota Korps Sukarela Palang Merah Indonesia (KSR PMI) Universitas Negeri Jakarta, Yaitu:

1. Rekan-rekan anggota Korps Sukarela Palang Merah Indonesia (KSR PMI) Universitas Negeri Jakarta diharapkan setelah mengetahui prosentase ini dapat melakukan tindakan pencegahan agar potensi cedera menurun.

2. Diharapkan kepada rekan anggota Korps Sukarela Palang Merah Indonesia (KSR PMI) Unit Universitas Negeri Jakarta memiliki pengetahuan yang cukup untuk menambah sumber referensi agar ketika menjumpai kasus cedera mampu memberikan penanganan dengan baik.

3. Anggota Korps Sukarela Palang Merah Indonesia (KSR PMI) Unit Universitas Negeri Jakarta turut serta aktif mengarahkan dan memberi informasi pencegahan cedera olahraga kepada masyarakat.

\section{DAFTAR RUJUKAN}

Cava, G La. Pengobatan dan Olahraga Bunga Rampai. Semarang: Dahara Prize, 1995.

Hardianto Wibowo. Pencegahan dan Penatalaksanaan Cedera Olahraga. Jakarta: Buku Kedokteran EGC, 1994.

Dimiyati et. al. Belajar dan Pembelajaran. Jakarta: Rineka Cipta, 2006.

Lukito Hasta et. al. Ilmu Pengetahuan dan Teknologi dalam Pembangunan Sosio Ekonomi Bangsa. Jakarta: Suara Bebas, 2011.

Sigi Gazalba. Sistematika Filsafat. Jakarta: Bulan Bintang, 1973.

Surajiyo. Filsafat Ilmu dan

Perkembangannya di Indonesia. Jakarta

: Bumi Aksara, 2010. 